\title{
Situated Crowdsourcing: a Pragmatic Approach to Encouraging Participation in Healthcare Design
}

\author{
Paul Marshall, Rebecca Cain and Sarah Payne \\ Digital Lab, WMG \\ University of Warwick \\ Coventry, CV4 7AL, UK \\ \{paul.marshall, r.cain.1, s.r.payne\}@warwick.ac.uk
}

\begin{abstract}
In this position paper, we outline a project being developed to improve the physical environment of a hospital emergency department to reduce staff stress levels and increase restorative opportunities. We outline a potential pragmatic participatory method to deal with staff members' limited time, which uses social software implemented on situated interactive displays.
\end{abstract}

Keywords-component; participatory design, health, emergency department, stress, restoration, situated crowdsourcing

\section{INTRODUCTION}

As part of the Participation in Healthcare Environment Engineering Programme ${ }^{1}$ at the University of Warwick, an interdisciplinary team from design, HCI, environmental psychology and computer science are working with members of staff at Derriford Hospital in Plymouth, UK to design and evaluate improvements to the physical environment of the Emergency Department. Initially, we are looking at the role played by the physical environment in causing stress and burnout in staff members.

Stress can result from directed attentional fatigue [19]. Directed attention involves focusing cognitive attentional facilities onto a specific topic while inhibiting attention to conflicting sources that are also competing for attention [20]. It is a voluntary process used during challenging tasks. Over time the ability to inhibit these unwanted demands becomes fatigued, concentration levels on the original topic wane and attention shifts to other activities. This can make an individual less competent at the job in hand, make rash decisions and become uncooperative and irritable [19]. It can also potentially result in stress [20]. In hospitals, there are a number of competing stimuli and demands on staff at any point in time. This potentially makes directed attention difficult, especially when an individual is already tired. Thus, directed attention is particularly liable to fatigue. It is therefore important that opportunities are available for staff to rest and restore these drained cognitive facilities.

The approach to be taken in this project is to engage staff in a participatory design (PD) process to both identify and ameliorate environmental stressors and to provide better opportunities for attention restoration. A PD approach is promising as it pools together the theoretical expertise and

\footnotetext{
http://bit.ly/gPTNsW
}

evidence-based design knowledge of researchers, with staff members' experiential and practical knowledge of their everyday environment, work practices and concerns.

However, there are a number of challenges in implementing traditional workshop-based PD methods in an Emergency Department. In particular, it is difficult to get staff to commit to intensive workshop sessions - especially those groups most at risk of stress and burnout. We are therefore developing an approach that draws heavily from recent attempts to adapt PD methods to use social software in order to engage distributed users (e.g., [24, 25]). Our approach will be to implement similar applications on situated technologies, able to be used by staff for short periods when they have a spare moment or are on a break. Thus, while we are not carrying out user centred design of pervasive healthcare applications, we are using pervasive applications to carry out user centred design in healthcare environments. We call this approach "situated crowdsourcing".

\section{PARTICIPATORY DESIGN}

Participatory design (PD) is a member of a family of approaches (including co-design, experience-based design, cooperative design and action research) to the design of technology, products, organisations and processes that aim to blur distinctions between researchers, designers and users. It grew out of Industrial Democracy projects carried out in Scandanavia in $1960 \mathrm{~s}$ and $70 \mathrm{~s}$, which adopted the explicitly Marxist goal of engaging trade unions in workplace design, against a backdrop of de-skilling and top-down imposition of changes by management. It has been argued that worker participation in design would lead to a number of benefits (e.g., $[5,6]$ ), including improving the knowledge base upon which systems are built; helping to manage people's expectations of technology and reducing resistence to its introduction; and increasing workplace democracy by enabling workers to participate in decisions that are likely to affect their work.

Notable early projects include DEMOS and UTOPIA (e.g., [14]). In the DEMOS project, workers in a locomotive repair shop documented how work processes might relate to computer systems and job roles. This new understanding was used to negotiate with management. The UTOPIA project worked with the Nordic Graphic Workers Union to develop computer systems for page layout and image processing in the newspaper industry. They developed several methods to encourage joint learning: engaging graphic workers in learning about the 
possibilities presented by computer systems, and researchers and designers in learning about the skills and practices of the graphic workers. In particular, a 'design-by-doing' approach was adopted where prototypes and mock-ups were used to enable workers to actively engage in the design process by carrying out the functions of their job in a concrete fashion. This enabled tacit knowledge of job processes to be elicited while iteratively critiquing and developing the designs.

By the end of the 1980s, participatory design approaches had begun to have an impact beyond Scandanavia, particularly in the area of human-computer interaction (e.g., [1]). However, as the geographical extent and popularity of participatory design has grown, the political focus has diminished, with most mainstream work now focussing on mechanisms and methods to facilitate the participation of different user groups and stakeholders (including management) in design (e.g., $[4,5,6]$ ). The main goal has become developing better systems rather than workplace democracy per se, with a diversity of approaches being developed that differ in terms of when they occur in the development process and the level of participation by user groups $[5,23]$.

Participatory design projects typically use tools and methods to gain insights into work processes and experiences. These include questionnaires, interviews, group discussion of experiences with existing technologies, work site visits to explore different implementation possibilities and detailed ethnographic observations of work practices as well as design approaches such as card games, co-operative prototyping, generation of storyboards and role-play to represent work (or leisure) practices (e.g., [21, 31]). Key to all of these methods is enabling potential users to envisage what it would be like to carry out a task or activity with a future technology, product or process, and/or helping the design team to think or experience what it would be like to be a user of their designs. They also provide a context in which participants can articulate their values in relationship to designed artefacts, which can be used to generate further design ideas, particularly in contexts where design possibilities or problems are poorly understood [15].

Most work in PD is still carried out in physical workspaces and for relatively small-scale design problems. However as technology becomes ever more ubiquitous, the scope of PD has broadened from a focus solely on workers and workplaces to diverse settings such as the home, leisure contexts such as museums, and on the move using mobile devices (e.g., [8]).

Kyng has argued that participatory design theory has failed to keep up with this changing context: "Today we lack structures to support users, especially non-wage earners, in design" [22, pg 9]. Furthermore, he has suggested that the main foci of PD research on methods and techniques to facilitate participation and on the political agenda of democratising decision-making and design in organisations has led to researchers overlooking a great many issues related to designing for the real world, such as the role of companies as producers and consumers of PD designs, issues of IPR and funding and the relationship of PD projects with sustainable outcomes. For example, PD projects are often described as taking place in "greenhouse" settings, shielded from some of the time constraints of everyday work, where workers are often given time off their everyday duties to participate in the project [21]. It is unclear whether this approach is suitable for a variety of real-world settings.

Indeed, there is a perception that while PD has been effective in generating small, separable designs, it has so far failed to work effectively on large scale organisational projects $[8,22,30]$. Furthermore, PD has typically focused on engaging with co-located project stakeholders rather than situations where stakeholders are separated by time or by space. There has been limited use of technology to support PD where designers and users are separated by large distances and where conventional workshop methods might not be possible [5]. Emerging work on distributed participatory design (e.g., [24]) is exploring how existing social software such as blogs, and voting applications might be appropriated to support design where users are not in the same place and might not even be known to each other or the research team [25].

\section{USER ENGAGEMENT APPROACHES IN HEALTHCARE}

Improving patient and staff experience of healthcare services and environments has become a central theme in both research (e.g., [2, 3]) and policy discussions (e.g., [13, 14]). A recent approach is to go beyond existing global measures of satisfaction to involve stakeholders in an on-going dialogue about personal experiences of healthcare and how services and environments might be improved.

While traditional participatory design work in healthcare environments has typically focussed on the development of IT systems (e.g., [30, 33, 34]), related approaches such as experience-based design (EBD) $[2,3,26]$ have been used more generally in service design. In EBD, staff and patients work together to capture and understand each other's experiences using stories. 'Emotion maps' are created to represent experiences of different 'touchpoints' with the service, such as the arrival of a letter, interaction with a receptionist or sitting in a waiting room. These emotion maps are then used to identify opportunities for service improvement.

While there appears to be some promise in the EBD approach, there has been little research carried out to evaluate its success. One potentially problematic aspect is that it relies on the standard PD "greenhouse" approach of intensive faceto-face sessions with stakeholders and the design team. While this works well in many hospital contexts, it does not seem suitable for an emergency department where staff are under significant time pressure and where patients may be stressed or distressed and will have little incentive to engage in a service improvement activity once they have completed their visit. Bowen et al. [10] document difficulties in engaging the staff in an outpatient department in an EBD project - they worried about the effect of their absence on colleagues, despite the research team paying for temporary staff to cover their work, and some dropped out of the project.

\section{DESIGNING A NEW PARTICIPATORY DESIGN METHOD}

Applying a PD approach to improving the physical environment of the Emergency Department we are working with seems to have significant potential: it fits well with policy guidance on including patients and staff in service improvement activities, as well as potentially improving the 
knowledge base upon which design decisions are made and increasing staff buy-in to any changes by enabling them to share ownership of the decision-making process.

However, as discussed above, there may be a number of problems in integrating a traditional intensive PD workshop approach into this kind of environment, where staff may be unlikely to be able to commit to an extended design process and patients will be difficult to engage and to keep engaged.

Therefore, we propose to design a new PD method that will be more appropriate for use in this context. We take as our inspiration, four approaches. Firstly, the emerging field of distributed participatory design, which aims to use software tools to support participation in the creation of computer systems by designers and end users who are separated by long distances (e.g., [25]) The online tool Owela for example, enables potential users to participate in discussions, freely add their own ideas, and comment on and rate others' suggestions [25].

Secondly, Crabtree et al.'s [12] use of “informational probes": kits of materials that can be used to gather snippets of information about individuals and their situated everyday concerns. The informational probe kit was designed for use by residents in a mental health unit and aimed to be less distruptive than conventional social science research methods like ethnography, while still providing (a limited amount of) information that could be used in design. From the informational probe approach we draw the perspective that small insights into the everyday concerns of the participants, able to be used in design, while they are clearly not as useful to the design team as an in-depth understanding still have some utility. This pragmatic approach has much in common with discount usability approaches in HCI (e.g., [27]) and the 'quick and dirty' approach to ethnography for system design [17]

Thirdly, the idea of crowdsourcing: outsourcing a function normally carried out by particular employees to an undefined group of people via an open call [16] Crowdsourcing has been proposed as an approach to facilitate public participation in planning projects [11] and used in high-profile media campaigns, such as the chef Jamie Oliver's challenge to encourage children to make better food choices, organised by the design firm IDEO [29]. In our study, we will put out an open call for ideas, but the group from which we draw suggestions will be limited to the staff of the emergency department.

Finally, the VoiceYourView system [35] is a situated intelligent kiosk that uses speech recognition and natural language processing to gather and classify opinions about the design of public spaces from members of the public. The system is also available as an iPhone application, enabling users to comment on some aspect of their location, which is logged using GPS [32]. We will aim to take a similar, but more expansive approach to gathering feedback from users of the Emergency Department. Furthermore, instead of using AI techniques to summarise feedback and suggestions, we will aim to support participants in making sense of the data themselves, by encouraging asynchronous dialogue, mediated by the system.
Our approach will be to create a participatory design kiosk on interactive surfaces to be positioned in one of more locations, including the staff room in the Emergency Department. The aim will be to engage staff members in using the system when they have a spare moment while on a break. Thus, the level of their engagement will be far short of that typical for a PD project, but it is hoped that will be possible to collect small amounts of relevant data from a larger number of staff members than would be possible in the more intensive approach. Staff will be repeatedly invited to contribute to different aspects of the participatory design process over a number of weeks, with tasks ranging from activities to help understand staff members' current restorative experiences both in and out of the workplace, such as simple questionnaires, to invitations to suggest changes to the current situation to aid restoration, to developing scenarios, selecting voting on and critiquing design ideas for further development, or annotating graphical representations of potential changes to the staff room. Thus, the goal is to create an ongoing dialogue relating to the physical design of the emergency department, open to all members of staff.

We will begin by systematically evaluating existing PD approaches to determine whether they will be suitable to be adapted to this new medium. We will select the most promising approaches and develop prototype systems, which we will trial at the Warwick University campus before finalising the PD applications to be used on the interactive surfaces in the Emergency Department.

\section{CONCLUSION}

The work outlined in this paper is still at the formative stage. We have identified an issue with current participatory design approaches given the constraints of working in an busy emergency department where staff have little time to engage in intensive participatory design sessions, particularly given current financial pressures on the British National Health Service. We have begun to develop an approach to engage with our participant group, drawing from a number of related appoaches, which we have termed "situated crowdsourcing". We hope to gain feedback on this approach at the User Centred Design of Pervasive Healthcare Applications workshop.

\section{REFERENCES}

[1] Bannon, L. (1991) From human factors to human actors. In Design at Work, (J. Greenbaum \& M. Kyng, eds), Lawrence Erlbaum Associates, Hillsdale.

[2] Bate, P. and Robert, G. (2006) Experience-based design: from redesigning the system around the patient to co-designing services with the patient. Qual Saf Health Care, 15, 307-310.

[3] Bate, P. and Robert, G. (2007) Toward more user-centric OD: lessons from the field of experience-based design and a case study. Journal of Applied Behavioral Science, 43 (1), 41-66.

[4] Beck, E. E. (2002) P for Political: participation is not enough. Scandanavian Journal of Information Systems, 14 (1), 77-92.

[5] Bergvall-Kåreborn, B. and Ståhlbrost, A. (2008). Participatory design: one step back or two steps forward?. In Proceedings of the Tenth Anniversary Conference on Participatory Design 2008 (PDC '08). Indiana University, Indianapolis, IN, USA, 102-111.

[6] Bjerknes, G. and Brattetieg, T. (1995) User participation and democracy: a discussion of Scandanavian research on system development. Scandanavian Journal of Information Systems, 7 (1), 73-98. 
[7] Björgvinsson, E. and Hillgren, P. (2004) On the spot experiments with healthcare. In Proceedings of PDC 2004, 93-101.

[8] Bødker, S. (2010) Introduction to the debate section: a short review to the past and present of participatory design. Scandanavian Journal of Information Systems, 22 (1), 1- 4.

[9] Bowen, S., Dearden, A., Wright, P., Wolstenholme, D. and Cobb, M. (2010a) Participatory healthcare service design and innovation. In Proceedings of the 11th Biennial Participatory Design Conference (PDC '10). ACM, New York, NY, USA, 155-158.

[10] Bowen, S., Dearden, A., Wolstenholme, D., Cobb, M. and Wright, P. (2010b) Co-designing better outpatient services for older people: inspiration stories for participatory design with health and social care institutions workshop, PDC 2010. Available at: http://research.shu.ac.uk/aces/uchd/external/wpcontent/uploads/2010/09/PDCworkshopStoriesUCHD.pdf

[11] Brabham, D. (2006) Crowdsourcing the public participation process for planning projects. Planning Theory, 8 (3), 242-262.

[12] Crabtree, A., Hemmings, T., Rodden, T., Cheverst, K., Clarke, K., Dewsbury, G., Hughes, J. and Rouncefield, M. (2006) Designing with care: adapting cultural probes to inform design in sensitive settings. In Proceedings of $\mathrm{Oz} \mathrm{CHI}$ 2003, Ergonomics Society of Australia.

[13] Couter, A., Fitzpatrick, R. and Cornwell, J. (2009) Measures of patients' experience in hospital: purpose, methods and uses. The King's Fund. Available at http://www.kingsfund.org.uk/document.rm?id=8429

[14] Department of Health (2010) A\&E clinical quality indicators data definitions. Available at http://www.dh.gov.uk/prod_consum_dh/groups/dh_digitalassets/@dh/@ en/@ps/documents/digitalasset/dh_122892.pdf

[15] Halloran, J., Hornecker, E., Stringer, M., Harris, E. and Fitzpatrick, G. (2009) The value of values: resourcing co-design of ubiquitous computing. CoDesign, 5 (4), 245-273.

[16] Howe, J. (2006) The rise of crowdsourcing. Wired Magazine, June 2006. Available at http://www.wired.com/wired/archive/14.06/crowds_pr.html

[17] Hughes, J., King, V., Rodden T. and Andersen, H. (1994). Moving out from the control room:ethnography in system design. In Proceedings of the 1994 ACM Conference on Computer Supported Cooperative Work. Chapel Hill, North Carolina, Oct., ACM Press, 429-439.

[18] Iedema, R., Merrick, E., Piper, D., Britton, K., Gray, J., Verman, R., and Manning, N. (2010) Codesigning as a discursive practice in emergency health services: the architecture of deliberation. Journal of Applied Behavioral Science, 46(1), 73-91.

[19] Kaplan S. The restorative benefits of nature: toward an integrative framework. Journal of Environmental Psychology 1995;15(3):169-82.

[20] Kaplan R, Kaplan S. The experience of nature: a psycholgoical perspective. Cambridge: Cambridge Univeristy Press, 1989.

[21] Kensing, F. \& Blomberg, J. (1998) Participatory design: issues and concerns. Computer Supported Cooperative Work, 7, 167-185.
[22] Kyng, M. (2010) Bridging the gap between politics and techniques: on the next practices of participatory design. Scandinavian Journal of Information Systems, 22(1), 49-68

[23] Muller, M. J. and Kuhn, S. (1993) Participatory design. Communications of the ACM, 36 (6), 24-28.

[24] Naghsh, A., Danielsson, K., Fischer, G., Bratteteig, T., Blomberg, J. and Nocera, J. (2006) Panel: Distributed-PD: challenges and opportunities. In Proceedings of PDC 2006.

[25] Näkki, P., Antikainen, M. \& Virtanen, T. Participatory Design in an Open Web Laboratory Owela. CHI08, ACM Press, (2008).

[26] NHS Institute for Innovation and Improvement. Experience Based Design. Available at: http://www.institute.nhs.uk/quality_and_value/experienced_based_desig n/the_ebd_approach_(experience_based_design).html [accessed $01 / 02 / 11]$

[27] Nielsen, J. Guerilla HCI: Using discount usability engineering to penetrate the intimidation barrier. In Bias, R.G. and Mayhew, D.J., editors, Cost-Justifying Usability, Academic Press, Boston MA, 1994, 245-272

[28] Nygaard, K. and Bergo, T. O. (1973) Planlegging, styring og databehandling. Grunnbok for fagbevegelsen ("Planning, management and data processing. Handbook for the labour movement"). (I), Tiden norsk forlag, Oslo, 1973.

[29] OpenIDEO (2010) How can we raise kids' awareness of the benefits of fresh food so that they can make better choices. Available at http://openideo.com/open/how-might-we-give-children-the-knowledgeto-eat-better/ [accessed 01/02/11]

[30] Pilemalm, S. and Timpka, T. (2008) Third generation participatory design in health informatics - making user participation applicable to large-scale information system projects. Journal of Biomedical Informatics, 41 (2), 327-339.

[31] Sanders, E. B.-N., Brandt, E. and Binder, T. A framework for organizing the tools and techniques of participatory design. In Proceedings of PDC 2010, $29^{\text {th }}$ November, 2010, Sydney, Australia, 195-198.

[32] Simm, W. (2010) Voice Your View Project. Availble at: http://itunes.apple.com/us/app/voice-your-viewproject/id387899428?mt=8 [accessed 01/02/11].

[33] Sjöberg, C. and Timpka, T. (1998) Participatory design of information systems in health care. Journal of the American Medical Informatics Association, 5 (2), 177-183.

[34] Weng, C., McDonald, D. W., Sparks, D. McCoy, J. and Gennari, J. H. (2007) Participatory design of a collaborative clinical trial protocol writing system. International Journal of Medical Informatics, 76S, S245-S251

[35] Whittle, J., Simm, W., Ferrario, M.-A., Frankova, K., Garton, L. and Woodcock, A. (2010) VoiceYourView: collecting real-time feedback on the design of public spaces. In Proceedings of Ubicomp 2010, ACM Press, 41-50. 